\title{
A PROPRIEDADE CONTRA A POSSE E A PROPRIEDADE 2
}

\author{
Ricardo Baitz*
}

\section{RESUMO:}

O presente artigo discute a propriedade e as mudanças nela introduzidas com o Estatuto da Cidade. A partir de uma perspectiva histórica de longa duração, investiga-se o processo que fragmenta a Propriedade em elementos distintos, tais como posse, propriedade, direito de construir e direito de superfície. Esses elementos são trabalhados enquanto uma necessidade do sistema que, encontrando limites, mobiliza o objeto (a propriedade), abstraindo-o.

PALAVRAS-CHAVE:

Propriedade, Posse, Estatuto da Cidade.

\section{ABSTRACT:}

The present article argues the property and the changes introduced in it by the Statute of the City (Federal Act number 10.257/2001, "Estatuto da Cidade"). From a long historical perspective, the process that breaks the Property into distinct elements (such as ownership, property, right to construct and surface right) is being investigated. These elements are studied as a system necessity which, finding limits, mobilizes the object (the property), abstracting it.

\section{KEY WORDS:}

Property, Ownership, Statute of the City.

\section{Introdução}

Existe, na riqueza produzida pelos muitos anos das ciências humanas, uma gama considerável de trabalhos versando sobre a Propriedade, em especial a territorial. Nessa gama, as interpretações são múltiplas e variam de acordo com a ótica da disciplina e ou o olhar do pesquisador, o que faz a Propriedade oscilar de fundamento a solução de todos os males.

A Propriedade enquanto temática é explorada desde os primórdios das ciências (ou desde a pré-ciência), quando, por exemplo, "inocentemente" os viajantes registravam em seus diários a articulação social nos territórios estrangeiros, apresentando sua dinâmica, que incluía a Propriedade de objetos e, às vezes, a do solo. Esse tipo de estudo fez várias escolas, e seu método - o comparado conferiu uma dupla utilidade, pois a descoberta de como o "outro" age, elucida a própria sociedade do pesquisador, garantindo que, ao conhecer o outro, também se faça um auto-retrato da sua especificidade, e que se balize o que simploriamente é posto como "natural" (do homem, da sociedade).

Desse momento, o que mais importa à discussão deste artigo é apontamento da presença da Propriedade em todas as sociedades e em todos os momentos históricos, pois mesmo nas sociedades onde o solo é comum, onde há a Propriedade Comunal, resta a Propriedade de objetos, que se inicia com 
aqueles tidos como pessoais ${ }^{1}$ e culmina nos que conferem status, poder ou algum relevo no contexto social.

Esses últimos, nas sociedades que conheceram o potlatch ${ }^{2}$ ou rituais similares, são ofertados em sua inteireza, como dádiva ou revide aos oponentes; são assim Propriedades das quais se dispõe para participação do ritual. Em síntese, nessas sociedades também se encontra presente sobre a forma Propriedade (a qual os juristas discorrem tão bem, quase delimitando como propriedade privativa), em especial ao que se refere sobre o dispor irrestritamente de um objeto.

\section{A Propriedade contra a posse e a propriedade}

“Nem todas as partes do rio correm igualmente. Além da espuma que se situa no alto, existem as correntes mais profundas. A espuma também faz parte do rio, mas ela só nos interessa se revela as correntes mais profundas. A espuma desaparece; os redemoinhos e as grandes correntes se conservam. Assim, o inessencial, o que não é causa de modo "profundo", se desfaz, desaparece. A "causa" é o lado calmo e profundo da corrente; é esse que recorta a margem e manifesta a orientação do rio. Mas, certamente, o rio em sua totalidade muda, já está mudando..." (LEFEBVRE, 1975, p. 199)

Se por um lado a forma Propriedade existe em diversas sociedades, por outro lado é apenas em condições muito específicas que seu conteúdo é movido abstratamente. Foi consoante a uma das mais notáveis conquistas da humanidade, a lógica formal, que se "chegou ao fim o que se chama falsamente de 'pensamento primitivo'"'3 e se abriu caminho para que a Propriedade fosse pensada abstratamente.

Abandonando sua noção original aquela mais simples, geralmente vinculada à certas particularidades, e portanto, associada a certas pessoas -, a Propriedade adentrou à forma tautológica, e aqui nos reportamos a sua primeira forma: a tautologia. Tornar toda e qualquer cuia "uma cuia" parece-nos bastante pouco, quase nada, quase o zero... Mas é a partir desse momento inaugural, em que os conteúdos foram esvaziados para receber uma forma, que se efetivou o progresso no sentido de uma sociedade, por assim dizer, "quente", dando início, faz-se necessário ressaltar, ao denominado processo civilizatório. $c[A]=c[$ ] $]$ (cuia de Antônio = cuia de José) suscita pôr em relação duas cuias, objetos em si infinitos de diferenças (cor, forma, tamanho, aspereza, durabilidade...).

Em outros termos, para que acontecesse a equivalência (" $=$ "), para que $c[A]$ pudesse equivaler a c[J], foi necessário o desenvolvimento de um pensamento extremamente abstrato, capaz de realizar logicamente um esvaziamento momentâneo de todos os conteúdos das duas cuias, colocandoas em relação através da forma cuia, ficcionando logicamente tal equivalência. Essa complexa operação beira a uma certa negligência ${ }^{4}$, mas foi através dela que a cuia (e demais objetos) pôde adentrar à sua forma mais pura, C = C, que corresponde a uma tautologia quase estéril, um passo decisivo para a fórmula da identidade $(A=B, B=C, A=C, .$.$) , e, para a troca! De um$ pensamento absoluto, no qual "a cuia é a cuia", chegamos a um pensamento relativo, no qual "uma cuia se equipara e equivale a toda e qualquer cuia". E isso através da identidade, que traz em seu bojo a equivalência, a troca possível, a conversibilidade e a reversibilidade dos termos, na medida em que a fórmula $A=B$ também dita o inverso, que $B=A^{5}$.

Se retornarmos nossos olhares à propriedade, em especial - mas não exclusivamente - a territorial, esta seria representada, em sua forma tautológica, pela equação inaugural $\mathrm{P}=\mathrm{P}$, ou Propriedade = Propriedade, o que permite esvaziar os conteúdos espaciais e trabalhar abstratamente o continente, o território. Uma grosseria aos olhos da Geografia ${ }^{6}$, mas que faz sentido no âmbito formal, aquele pelo qual o Direito se enveredou. 


\section{Da equação inaugural às suas derivações}

"Sob a imobilidade aparente, a análise descobre uma mobilidade oculta. Sob a mobilidade superficial, ela atinge estabilidades, auto-regulações, estruturas e fatores de equilíbrio. Sob a unidade global, ela revela diversidades; e sob aparências múltiplas, uma totalidade." (LEFEBVRE, 1965)

Se por um lado a fórmula inaugural permite pensar abstratamente a propriedade, inclusive dar-lhe tratamento próximo às mercadorias ao estabelecê-la no plano da equivalência, por outro lado ela admite um progresso, não se contentando em se fixar. 0 pensamento fixo, estagnado, parado, também representa a redução, pois aquilo que freia as potencialidades tende a se atrofiar pelo não uso. Guardadas no armário por muito tempo, as sementes envelhecem, as máquinas deterioramse e o pensamento se deixa estar em algum lugar do passado, aquele do tempo de sua formulação, longe do presente, portanto. Por isso é importante recuperar que o movimento de abstração da propriedade - fundado na antigüidade clássica, que trouxe no seu bojo a lógica formal e com ela, a equação $P=P$ - admite um progresso, um algo a mais que a tautologia. Esse algo a mais passa agora a ser desvendado, sob a hipótese de se tratar de uma decomposição lógica de um dos termos.

Se adentramos à história desse período, verificamos que, logo após a tautologia que permitiu a troca das Propriedades, outro processo de abstração, a saber, aquele da distinção de dois dos seus elementos: a posse e a propriedade. De modo que a equação proposta $(P=P)$, conquista penosa à humanidade, em pouco tempo se fez ultrapassada, com seus termos substituídos pelos elementos posse e propriedade. Matematicamente a fórmula passou a ser representada por $\mathrm{P}=\{\mathrm{p}, \mathrm{o}\}$, sendo [p]ropriedade e $p[o] s s e$ os elementos do conjunto [P]ropriedade ${ }^{7}$. Da tautologia, que consiste em pensar toda propriedade como uma propriedade (generalização), surgiu a possibilidade de pensar a Propriedade separando o detentor da coisa de seu proprietário ${ }^{8}$. E imaginar que alguém possa ser o proprietário de um objeto sem, contudo, o investir (antes o inverso: permitir a outro sua "vestidura") é uma operação complicadíssima, com um alto grau de abstração, que outras sociedades desconheceram, o que justifica certo sucesso da racionalidade clássica.

Desse processo de abstração sumariamente potente, cumpre ressaltar que a lógica formal foi aquela capaz de cindir o que era uma unidade em propriedade e seu decalque, a posse: esse é um modo possível (mas não o único ${ }^{9}$ ) de compreender o instituto do direito de Propriedade, que conserva a forma Propriedade, mas modifica seus conteúdos, abstraindo-a ${ }^{10}$. Está revelada, agora, a chave desse texto.

\section{Do abstrato ao [abstrato] concreto}

“-De quem é essas terra? -Do coroné.

-E pra lá? -Também é do coroné.

- Puxa. -Tem muito chão

-Quem? -O coroné."

(ANDRADE, 1974, p. 219)

Além de lógico, esse processo é concreto na medida em que tende, meio aos diversos agentes sociais, à interferência no real. De modo que essa abstração, concreta, através desses agentes, trouxe resultados bastante práticos à humanidade (compreendida aqui em sua inteireza). Tais resultados possibilitam a conquista de territórios cada vez mais distantes, culminando na demarcação de cada $\mathrm{m}^{2}$ do planeta Terra, territórios esses adjetivados de públicos ou privados, comuns ou privativos, que a partir de então passaram a pertencer a alguém, corpóreo ou incorpóreo. Face ao modelo "bárbaro" de sociedade, na qual o solo é simultaneamente apropriado e abandonado à medida que se avança com a conquista de novos espaços e o descarte dos que ficam para trás ${ }^{11}$, o modelo "civilizado" de sociedade, ao separar posse e propriedade, permitiu a acumulação 
para além do uso, sobre tudo o que fosse passível de se exercer o poder de domínio (ou simplesmente domínio, para evitar a redundância) ${ }^{12}$. Assim foram pilhados os territórios conhecidos por Roma, que conferia aos povos dominados o direito de posse, reservando para si o direito de propriedade mediante o exercício do domínio; e pelo mesmo meio - a força - esse modelo se universalizou mais tarde, abarcando o mundo, as Américas e suas civilizações.

A mobilização dos conteúdos da propriedade (mas não só ela) deu flexibilidade a um mundo estático, "frio"13. Esse talvez seja seu grande mérito, e esse registro precisa ser feito. Considerando-o, resta-nos ir além e compreender, nova e insistentemente, que um processo de abstração, enquanto uma forma de pensamento, comporta um progresso, com novas etapas que "superam" a anterior, aprimorando-a. Esse progresso existe, e é o tema dos próximos parágrafos, que analisam a propriedade atualmente, retendo todo esse entendimento do passado como esquiva aos fáceis idealismos modernos.

\section{O uso é transformado numa qualidade}

De uma concepção de Propriedade enquanto uma unidade chegou-se, através da lógica, à sua decomposição em dois elementos: propriedade e posse, $P=\{p, 0\}$. Mas, além de forma, a propriedade admite conteúdos, e por assim dizer, um uso (ou utilidade), o qual pode ser reduzido e se transformar em utilitarismo. Salta-se agora para uma história mais recente, que já foi naturalizada para muitas pessoas, inclusive pesquisadores. A razão estatista (razão de uma época, complementa-se), trabalhando a propriedade enquanto um certo uso (uso recrudescido, ressalva-se), inclinou-se a também separar esse elemento. Primeiramente, tornando o solo rural diferente do urbano (uma propriedade na cidade é diferente de uma propriedade no campo em termos jurídicos, por exemplo), de modo que a equação se tornou, a partir de então, $P=\{(p$ $+\mathrm{t}$ ), o \}, sendo a partícula ' $\mathrm{t}$ ' o tipo de propriedade $^{14}$ (rural ou urbana).

Exercendo o poder de normatizar o território, o poder público pôs no espaço sua razão, dividindo a cidade em múltiplos usos: territórios industriais, comerciais, residenciais, que podem ou não se justapor (uma área residencial pode - ou não - admitir alguns tipos de comércio, por exemplo, admitindo mais de um uso para a mesma porção do espaço, de acordo com a vontade do seu proprietário) ${ }^{15}$. Limitando o exercício do poder de propriedade individual ao submetê-lo à lei de zoneamento, de ordem pública, ele conseguiu, a partir desse momento, dar relevância e peso ao elemento uso da propriedade, mobilizando a equação anterior para $P=\{(p+t+u), o\}$, ou seja, Propriedade $=\{($ propriedade + tipo + uso $)$, posse $\}$, ainda que a partícula $p$ e $t$ surjam, nesse momento, enquanto uma qualidade da propriedade por ocasião da sua imutável posição territorial. A produção do zoneamento foi também a produção de uma raridade, cada vez mais aprofundada, nas áreas urbanas.

\section{A Propriedade recebe novos elementos}

A Propriedade, que foi tomada abstratamente e depois cindida em posse e propriedade, que por sua vez teve desenvolvidas pela administração pública as qualidades de um certo tipo e uso, encontrou recentemente novos elementos: solo criado ${ }^{16}$, direito de superfície... Não importa classificar se tais termos foram vislumbrados pela esquerda ou pela direita: assim como a abstração inicial não foi ideologicamente ingênua (haja vista como ela foi possível) e produziu resultados bastante conhecidos, esses decalques também o farão; e o fato desses elementos estarem fundados na mesma lógica apenas corrobora essa indicação. Mais importante que o apontado anteriormente é encontrar as fissuras dessa grade e localizar o momento em que essa nova gama de abstrações entra em cena, pois sua entrada à forma da propriedade (do solo) não se realiza por abstração pura, como se a lógica 
se realizasse por si própria, de maneira autônoma, mas por uma necessidade do sistema que alcançou seus limites nos negócios e precisa se reinventar a fim de prolongar sua vida, o que se compõe à teoria marxista e localiza a vivência de uma crise $^{17}$.

Foi assim que a administração pública, encontrando certos limites de reprodução (em especial nas cidades, onde a terra, um bem cuja natureza é monopolista por não poder ser reproduzido, rapidamente se fez finita e rara), flexibilizou todo o ordenamento jurídico sobre o solo (e, em especial, seu entendimento, que originalmente era "iluminista"18) para que além da propriedade e da posse, o direito de Propriedade fosse concebido enquanto direito de criar solo. Nessa figura, a possibilidade de construir pisos (ou andares) aéreos ou subterrâneos, criando áreas maiores que o terreno possui, foi isolada como um direito em si autosuficiente, real ${ }^{19}$, o que sugere o destaque do direito de construção do direito de propriedade. Sob a forma de Operações Urbanas ${ }^{20}$, os interessados em construir grandes edifícios que extrapolam o zoneamento "normal"21 podem fazê-lo nas regiões delimitadas por esse instituto, bastando para isso a compra de "aditivos" à propriedade que podem ser adquiridos da própria municipalidade ou de particulares, vista serem direitos reais, representados por papéis de livre negociação. Com a raridade do espaço horizontal criou-se a raridade do espaço vertical, ainda que fictícia, sob a representação de títulos que na cidade de São Paulo chamam-se CEPACs (ou Certificados de Potencial Adicional de Construção), que são igualmente finitos, embora sejam apenas números. Essa finitude, estabelecida por critérios "científicos" que consideram o "suporte" da região para novas construções, serve para dar efetividade aos negócios particulares, em especial os que envolvem especulação à custa de uma antecipação à municipalidade, na medida em que se constituem - e que são apresentados, sob a forma de leilão - como uma nova raridade. Com o solo criado e a outorga onerosa do direito de construir, a nova fórmula da Propriedade, uma equação em metamorfose, se aprimora e passa a ser ditada por um conjunto mais complexo, adicionado de um novo elemento, o direito de construir, representado pela partícula " $\mathrm{C}$ ": $\mathrm{P}$ " = $\left\{p^{\prime}, o^{\prime}, c\right\}$, ou $P^{\prime \prime}=\left\{(p+t+u)^{\prime}, o^{\prime}, c\right\}$. Essa fórmula, abstrata, ganha concretude à medida que se visita as áreas de Operações Urbanas, onde o gabarito da cidade aumenta vertiginosamente, e a cidade enquanto negócio se aparenta infinita, embora seja expressão de um limite, e de uma crise de reprodução ${ }^{22}$.

Ademais, as Operações Urbanas admitem a emancipação do uso enquanto uma qualidade do território ao permitir que o proprietário modifique essa regra do zoneamento, adquirindo títulos da municipalidade. Assim, um terreno residencial de coeficiente de aproveitamento 2 pode ter seu coeficiente majorado para 4, e o uso modificado para comercial. Com essa emancipação, a equação se torna $P^{\prime \prime}=\left\{(p+t)^{\prime}, o^{\prime}, u^{\prime}, c\right\}$, com o uso surgindo pela primeira vez enquanto elemento, e não mais como uma qualidade.

Novos institutos, como o direito de superfície ${ }^{23}$, introduzidos pelo Estatuto da Cidade (lei federal 10.257, de 2001) ainda não produziram resultados significativos, mas têm ensaio marcado. Na cidade de São Paulo seu laboratório será uma grande área de três proprietários (Municipalidade, Telefônica ${ }^{24}$ e CPTM), onde formula-se a criação de um novo bairro, o Bairro Novo, objeto de um concurso público arquitetônico em 2004. Sabe-se que nenhum desses proprietários cederão suas propriedades ${ }^{25}$, mas apenas o decalque da superfície, permitindo ao superficiário o uso, mediante pagamento, por períodos predeterminados.

Nosso "confuso" conjunto recebe mais um elemento, um novo decalque: a [s]uperfície: $\left.\mathrm{P}^{\prime \prime \prime}=\{(\mathrm{p}+\mathrm{t}))^{\prime \prime}, \mathrm{o}^{\prime \prime}, \mathrm{u}^{\prime \prime}, \mathrm{c}^{\prime}, \mathrm{s}\right\}$, e faz unir ao proprietário, ao posseiro, ao especulador (que compra os CEPACs objetivando sua revenda por maior valor) a figura do superficiário, que possui 
o direito de superfície, conforme o art. 22 (dentre outros) desse Estatuto.

Não é certo o papel desse novo personagem, o superficiário; apenas se sabe que sua função é de segundo figurante, pois ele é o mais "despossuído" desse conjunto (inclusive quando comparado ao posseiro), pois aquele que usufrui da superfície pode estar condicionado a procedimentos jurídicos diferentes da tradicional reintegração de posse (instrumento pelo qual o proprietário busca, através de seu direito de propriedade, reestabelecer a posse ao seu domínio) ou da desapropriação. O rito para quem descumpre as cláusulas do direito de superfície ainda não está completamente esclarecido pela jurisprudência, mas enquanto latência, já se anuncia a possibilidade de que quem "comprar" um apartamento construído com o conceito de solo criado, sobre o direito de superfície, amarrado a um direito de propriedade alheio, terá sua "propriedade" (o bem imóvel) bastante volatilizada, especialmente quanto aos procedimentos cabíveis em caso de inadimplemento, para citar um único exemplo ${ }^{26}$. Por sua vez, o usucapião torna-se brando, quando não ineficaz, vista que esse instituto supõe a posse mansa, e não a detenção da superfície ${ }^{27}$.

Chega-se, agora, ao final dessa segunda parte do texto, com o seguinte quadro propositivo $^{28}$ para a compreensão do direito de propriedade:

\begin{tabular}{|c|c|c|}
\hline \multicolumn{3}{|c|}{ A Propriedade em Movimento } \\
\hline $\begin{array}{l}\text { Grau de } \\
\text { abstração }\end{array}$ & Equação & Elemento Mobilizado e ou Emancipado \\
\hline 0 & $P$ & - \\
\hline 1 & $P \equiv P$ & Propriedade \\
\hline 2 & $P^{\prime} \equiv\{p, 0\}$ & propriedade e posse \\
\hline 3 & $P \equiv\{(p+t), 0\}$ & tipo (rural, urbano) \\
\hline 4 & $P \equiv\{(p+t+u), 0\}$ & udo (comercial, residencial, industrial) \\
\hline 5 & $\begin{array}{c}P^{\prime \prime} \equiv\left\{p^{\prime}, o^{\prime}, c\right\} \\
\text { ou } P^{\prime \prime} \equiv\left\{(p+t+u)^{\prime}, o^{\prime}, c\right\}\end{array}$ & direito de construir \\
\hline 6 & $P^{\prime \prime} \equiv\left\{(p+t)^{\prime}, o^{\prime}, u^{\prime}, c\right\}$ & direito de uso destacado da propriedade \\
\hline 7 & $P^{\prime \prime \prime} \equiv\left\{(p+t)^{\prime \prime}, o^{\prime \prime}, u^{\prime \prime}, c^{\prime}, s\right\}$ & direito de superfície \\
\hline
\end{tabular}

\section{Do entendimento do lógico para uma estraté- gia da prática}

O "problema" da propriedade se torna mais complexo à medida que surgem os novos decalques, os novos elementos. Qualquer tentativa de solução passa necessariamente, agora, pela compreensão do processo de sua produção. É remontando à maneira pela qual essa operação se efetiva que se pode averiguar que posse e propriedade (para nos atermos a dois termos apenas, "simplificando" o conjunto que se sabe ser mais complexo) são complementares da Propriedade, e não seus antônimos (formais ou dialéticos). 
Vários geógrafos notaram que apesar de serem elementos distintos, cada um deles permite - se forem devidamente trabalhados a reunião do outro elemento para a restituição da Propriedade numa unidade (sobre a Propriedade do solo, sabe-se que o proprietário pode pleitear a reintegração de posse perante o invasor, bem como o posseiro "manso" pode exigir o usucapião da propriedade investida), de forma que há sempre um fino (mas resistente) fio unindo esse dois elementos, permitindo sua comunicação e aproximação, ou seja, sua reunião. Contudo, ao lado do conhecimento desse importante aspecto, outro tem sido eclipsado, e às vezes deixado no desconhecimento: trata-se do primeiro, que situa posse e propriedade como complementares. Muitas vezes a posse é apresentada como uma oposição à propriedade, embora ela possa ser, no máximo, seu reflexo invertido. A constatação ou persistência da posse apenas evidencia a presença/ausência da propriedade, não resolvendo o "problema", impossível de se extinguir com essa proposição. Para isso é preciso compreender que na história o oposto da propriedade privada (aquela que priva as demais pessoas) não pode ser a posse, mas a Propriedade Comunal. Em termos dialéticos, a propriedade passa a ser compreendida enquanto o termo positivo, a posse enquanto o termo negativo, e a Propriedade Comunal a síntese ou momento de superação. Superação inexistente quando se permanece nos dois termos, ou mesmo quando se objetiva a reunião deles (o posseiro que consegue a propriedade mas não a eleva à propriedade Comunal apenas reitera a lógica da propriedade privada, e faz dialética de dois termos, sem superação, tornando os termos estáticos e conservadores).

O processo e sua superação são melhor elucidados quando se analisa como esse instituto vem se desdobrando abstratamente, em outros âmbitos, como no caso da propriedade intelectual. Nesse campo são formadas fortunas, não aleatoriamente, em múltiplos segmentos, como os de software de computadores, estúdios fonográficos e cinematográficos. Em comum, o que reúne essas empresas é a venda de uma fina camada de direitos aos "consumidores", camada essa que não atinge a Propriedade. A venda de um CD de música permite que o comprador ouça as faixas, na ordem preferida, sempre que desejar. Mas ele não pode executar, sob qualquer pretexto, uma faixa qualquer do CD numa festa, ainda que "particular", pois a cessão de direitos de ouvir as melodias restringe sua execução pública. Não pode o comprador, igualmente, reproduzir o CD de áudio para um amigo, ou fazer uma cópia de segurança para manter no carro, sob pena de infringir o contrato com a empresa fonográfica. O mesmo - e mais - se aplica ao software: certos programas não permitem que o comprador, mesmo desistindo de usar o produto, possa vendê-lo a qualquer interessado, por ser proibida a revenda ou doação. Em outras licenças, é impedida a transferência do software de uma máquina para outra, ainda que as duas sejam do mesmo comprador (e note-se: não se trata de usar o programa em dois computadores simultaneamente, mas de transferir o programa de um computador, mais antigo, para outro, mais novo); e existem casos onde há regulação de quantos usuários poderão acessar o software, ainda que todos partilhem da mesma máquina. Se não se pode copiar a música ou o programa, se não se pode tocar o CD em público, se não se pode transferir o programa de um computador para outro, o que se compra de fato quando se adquire um software ou um $C D$ de música? Resposta: um pequeno decalque de Propriedade, que permite o direito de escutar o som ou executar o software, e nada mais, ficando todos os demais direitos assegurados a seu proprietário. Com esse tipo especial de "decalque", o proprietário vende algo muito melhor que sua Propriedade, pois a conserva, e é sobre essa forma toda especial de disponibilizar a Propriedade sem, de fato, abrir mão dela que se fazem as grandes fortunas nesse meio (a propriedade em si não cria a fortuna, ao máximo a expressa, pois é o trabalho 
a medida de todo valor; contudo, através dessa estratégia são "recolhidos" e acumulados valores, ainda que a propriedade em si, reiterase mais uma vez, não produza valor ${ }^{29}$ ).

Trata-se de um processo bastante refinado de abstração, cujas similaridades com o que envolve a propriedade do solo fazem deslocar seu ápice. O estágio atual deve ser compreendido não através de reflexos, mas de desenvolvimentos desiguais e combinados, com seu vértice representado pela propriedade intelectual, restando à propriedade do solo uma condição de atraso para a qual o capitalismo busca uma "atualização", através dos mecanismos já mencionados (nos quais incluise o Estatuto da Cidade). A investigação se desloca para a propriedade intelectual, e nos interessa em especial saber como, nesse meio, as batalhas estão se realizando.

\section{A guerrilha lógica}

Reconstituição de um momento histórico, na década de 80: após um período de batalhas "heróicas", no qual frente aos programadores "de mercado" existiam os de "pesquisa", a vitória parecia assegurada ao mercado que avançava indistintamente, comprando a produção intelectual daqueles dispostos a vendê-la, por um lado, ou incorporando aquilo que era tornado domínio público, pertencente a todos, e por isso passível de apropriação, inclusive pelas empresas ${ }^{30}$, por outro lado. As tentativas de confronto com a propriedade privada eram ineficazes, pois a transformação da propriedade privada em propriedade pública (de software privado em software de domínio público) apenas permitia sua apropriação irrestrita, pouco inibindo o sentido do mercado, que consiste em fazer o software girar enquanto mercadoria $^{31}$

Havia um erro de estratégia, e os hackers, altamente gabaritados na lógica formal, o descobriram: era preciso ações procedimentais, e não genuinamente revolucionárias (abolir a propriedade, lançando- a como de domínio público era revolucionário, mas capturável), de modo a minar o inimigo em seu interior, compondo-se à sua lógica (coisa que o Domínio Público não permite, por ser uma racionalidade exterior ao processo), de forma a levá-la ao seu limite interno, realizando o inverso daquilo para o qual foi projetada. É então que aconteceu uma revolução digna do adjetivo genial: de uma concepção que negava a propriedade privada passou-se a afirmá-la, tornando tudo o que se produzia anteriormente sob licença de "domínio público", em proprietário. Com isso, assegurando o direito de propriedade, os hackers garantiram o destino de sua produção ${ }^{32}$, evitando a captura da propriedade intelectual pelas empresas que, com pequeno investimento, tornavam seu (através de incorporações a sistemas mais complexos ou derivados) o trabalho liberado como de domínio público.

Compreendendo que ser proprietário assegurava também dispor irrestritamente da criação, fez-se um decalque na propriedade permitindo sua reprodução a quem interessasse, desde que nesse processo não houvesse ganhos superiores ao da mídia de suporte (CDs, disquetes, que são materiais que custam pouco). Em modelos mais abusados de decalques, fez-se a permissão irrestrita de cópia, reservado o direito integral de propriedade, inclusive o da propriedade derivada, tornando esse tipo de software um "vírus", fazendo com que tudo o que ele tocasse se transformasse em software sob licença "GPL" 33 , e assim em propriedade fora da forma mercadoria; ou melhor, numa forma que é contra a mercadoria e também contra a propriedade, ainda que isso se dê afirmando-a!

Foi assegurando a condição de proprietário que se pôde estabelecer a propriedade não como propriedade pública (que é o espelho invertido da propriedade privada), mas enquanto propriedade comum (ou comunal, indicando estágio de superação, para além da dicotomia público-privado), protegendo-a inclusive de seu criador ao dar-lhe autonomia e vida própria através de dispositivos que 
impeçam a revogação do termo, no todo ou em partes. Operações lógicas, mas que no seu "pano de fundo" demonstram um profundo entendimento da maneira de operar da sociedade (que não é lógica, mas se esforça para sê- $\left.\mid \mathrm{o}^{34}\right)$, mediante uma telescopagem do local com o universal ${ }^{35}$.

Em quadro sintético, a GPL, atuando na distribuição, atingiu a produção ao contaminála, impedindo que o resultado do trabalho se transformasse em mercadoria (ao menos em mercadoria tal qual se conhecia pelas outras licenças de software). Seu aspecto mais importante é o caráter viral e o tipo de guerra que permite, inserindo-se na lógica interna, fazendo-a ir ao seu limite, para então extrapolála, sugerindo seu oposto. Ela indica, ademais, uma nova forma de lutas de classes, que Lefebvre denomina por "formas modernas de lutas de classes" (LEFEBVRE, 2005);

\section{Apontamentos sobre o solo: para além do público e do privado}

Com esses elementos recupera-se a discussão da propriedade do solo, e a do Estatuto da Cidade. Já está descrito o sentido abstrato que a propriedade ganhou nesse processo. Também está descrito que tal movimento não cessou, e que, com ele, a tendência da propriedade é se tornar cada vez mais abstrata. Feito isso, ainda há tudo por se fazer, pois se o pensamento não é apenas descrição, mas suporta ação, e por isso cumpre agora desenvolver a estratégia possível frente a essa lógica que fragmenta, que retira camadas de um objeto para reinserí-lo enquanto mercadoria. E qual seria ela?

Os limites da pesquisa - e do pesquisador - possibilitam a apresentação de apenas dois modos de resolver o dilema, até o momento. O primeiro, compreendendo que a Propriedade é fracionada em posse, propriedade, direito de construir, solo criado, imagina poder restituí-la numa unidade, como nos momentos primitivos. O segundo, compreendendo que um objeto uma vez fracionado (ainda que esse fracionamento se faça logicamente) nunca deixará de ser esses pedaços, inclina-se a pensar em compor-se a essa lógica para restituir a propriedade do solo enquanto propriedade comum. O pesquisador, exercendo a propriedade de suas idéias e desse texto, recusa o primeiro momento e inclina-se ao desenvolvimento do segundo.

Bom seria se os objetos fossem puros, e pudessem ser facilmente catalogados como bons ou ruins, simplesmente. Isso facilitaria por demais o labor de um filósofo, assim como o trabalho do artista caso no mundo houvesse apenas as cores puras. Mas, para o azar de alguns pensadores, entre o bom e o ruim há um espectro praticamente infinito de possibilidades. E, no arco-íris, cada cor se intensifica até atingir um auge; então ela decai, gradualmente, deixando-se modificar, até atingir uma coloração diversa, transformando-se na cor adjacente. Classificar o Estatuto da Cidade como bom ou ruim seria adentrar a essas formas duais e simplórias de entendimento, ou seja, seria uma redução.

Ele não é uma negatividade pura. Ao contrário, quase toda análise preliminar encontra nele positividades através de instrumentos para uma luta social horizontal, tal como a Concessão de Uso Especial para Fins de Moradia. Esse mecanismo jurídico, por exemplo, engendra a possibilidade de criação de territórios mais livres, "quase" comuns. "Quase", porque os territórios sustentados por esse tipo de intervenção preservam o modo estatista de pensar o espaço - o que é o bastante para suscitar desconfiança -, especialmente pela possibilidade de transferência da concessão para outro local se a área concedida for destinada, a qualquer m am ento, a projto de urbanizaçãós .

Mas além das positividades e negatividades, o Estatuto carrega consigo um sentido mais profundo, e o caminho desse texto foi o de explorar uma tal correnteza, 
demonstrando de que forma, com esse Estatuto, a propriedade territorial no Brasil ganhou, efetivamente, um grau mais abstrato como compensação aos limites que lhe são internos ${ }^{37}$. A propriedade progrediu: e isso foi uma conquista, um progresso. O que muda radicalmente a maneira de guerrear na luta pela cidade: a propriedade mudou, e com ela as batalhas pelo morar se transformaram e ganharam outras possibilidades.

Por muito tempo os movimentos sociais foram acusados de fazer o jogo do inimigo ao exigirem a propriedade privada dos terrenos conquistados. Isso, diziam os opositores, reforçaria o caráter de bem negociável, permitindo a compra e venda dos lotes, o que é bastante verdade. Assim como também o é o fato de que todo chão tem um proprietário, e que se o movimento social não exigir a titularidade das terras, a municipalidade a reterá, podendo mobilizar em qualquer momento a população lá situada por "interesse público". Com o capitalismo e a forma capitalista de pensar o mundo (o Estado é uma expressão), a propriedade se tornou efetivamente, um problema a ser pensado, mesmo que a única coisa que se queira é o direito de ir, vir e permanecer onde se vive. Como amenizar esse problema sem cair num pensamento idealista?

O passado auxilia. A GPL, resultado desse processo de abstração num tipo muito especial de direito, demonstra ser possível decalcar suavemente parte da Propriedade de maneira a restabelecê-la enquanto uso, permitindo o gozo e a festa. Sua luta evidencia que o movimento de abstração de um objeto é plástico, e que com ele podese também desenvolver o outro da alienação, fazendo com que a propriedade escape do domínio público e privado, e se situe no âmbito do comum. E eis o paradoxo: tal possibilidade não se dá enquanto uma negação da Propriedade ${ }^{38}$, mas acirrando a figura do proprietário que detém direito irrestrito sobre seu "bem", podendo fazê-lo adentrar ao jogo na contramão do carteado ${ }^{39}$.

Paradoxo? Esse projeto carrega consigo contradições; mas de ordem formal. Seu pressuposto é, com efeito, o indivíduo; mas não um indivíduo utopista que se crê autosuficiente. Ao contrário, falamos aqui de um indivíduo consciente do processo social que o emancipou, consciente que sua individualidade é, antes de tudo, coletiva; consciente que ele é fruto de uma luta contra a coletivização que dissolvia as possibilidates de se ser "alguém" (ANDRADE, 1995, p. 55, p. 127). É também um projeto contra o individualismo abstrato, cuja realização concreta resultou na sociedade que bem conhecemos. Seria uma "luta mortal" (Lebenskampf), no sentido hegeliano do termo, contra dois flancos? O peso das palavras amedronta, mas dá a dimensão (medida) da batalha. É também uma luta de classes, que encontra sua forma moderna de combate, na qual proliferam táticas subterrâneas ao passo que a luta horizontal é aposentada quase compulsoriamente, por se fazer quase ineficaz.

Inovar o estatuto da Propriedade, minando-a da condição de mercadoria (bem negociável, comprável), re-estabelecendo-a enquanto uso, enquanto propriedade comunal: é uma via de riscos, que para se efetivar necessita de uma profunda pedagogia social, a fim de superar a ideologia da propriedade privada, fazendo nascer um novo tipo de homem, que recupere todas as potencialidades da história e se desprende das suas repressões. 


\section{Notas}

${ }^{1}$ A cuia e a lança são bons exemplos de objetos pessoais. Estão, de certa forma, tão atados à pessoa que ospossui, que se fundem ao seu proprietário, justificando o fato de acompanharem seu "dono" para além da vida. São vários os relatos etnográficos de rituais fúnebres nos quais, curiosamente, os objetos íntimos são mantidos com o morto, por lhe serem "próprios", fazendo-lhe referência direta, o que torna a lança "em si" não uma lança apenas, mas uma extensão daquele que deixou a vida. Ela perece com o ente da comunidade, ainda que haja uma escassez coletiva e no plano racional seja interessante o reaproveitamento do objeto por outros entes da coletividade.

2 “(...) em sua forma mais típica, encontrada na tribo dos Kwakiutl, o potlatch é uma grande festa solene, durante a qual um grupo, com grande pompa e cerimônia, faz ofertas em grande escala ao outro grupo, com a finalidade expressa de demonstrar sua superioridade. A única retribuição esperada pelos doadores, e que é devida pelos que recebem, consiste na obrigação de estes últimos darem por sua vez uma festa, dentro de um certo período, se possível ultrapassando a primeira. Este curioso festival de donativos domina toda a vida comunitária das tribos que os praticam: os rituais, as leis, as artes. Qualquer acontecimento importante pode servir de pretexto para um potlatch, seja um nascimento, uma morte, um casamento, uma cerimônia de iniciação ou de tatuagem, a construção de um túmulo, etc. É costume o chefe oferecer um potlatch sempre que constrói uma casa ou um totem. No potlatch, as famílias ou clãs apresentam-se sob sua forma mais brilhante, cantando suas canções sagradas e exibindo suas máscaras, enquanto os feiticeiros, possuídos pelos espíritos do clã, entregam-se à sua fúria. Mas o principal é sempre a distribuição de bens. O promotor da festa dissipa nesta todas as posses de seu clã. Contudo, o fato de participarem da festa dá aos outros clãs a obrigação de oferecer um potlatch em escala ainda mais grandiosa. Caso contrário, destróem seu nome, sua honra, seu emblema e seus totens, e até seus direitos civis e religiosos. O resultado de tudo isto é que as posses de toda a tribo vão circulando por entre as "grandes famílias", ao acaso." (HUIZINGA, 2004, p. 66).

${ }^{3}$ Cf. LEFEBVRE, 1975, p. 166. Nesse trecho da obra, Henri Lefebvre apresenta um quadro geral da "história da lógica formal", situando as condições que permitiram ao pensamento grego a abstração e o desenvolvimento deste.

4 “Essa eliminação só pode levar a uma negligência, a uma supressão pura e simples, no caso do entendimento, isolando-o a si mesmo, converterse em entendimento metafísico. Quando ele realiza normalmente sua função, a eliminação do conteúdo é apenas momentânea. O pensamento (neste caso, a razão) toma uma consciência mais aguda desse conteúdo através do ato que determina uma sua parte restrita; e a razão, em seguida, preocupa-se em voltar ao conteúdo a fim de captá-lo em sua totalidade e em sua vida. A eliminação momentânea não é uma supressão, mas uma negação dialética, que ainda envolve o que é negado." Cf. LEFEBVRE, 1975, p. 131.

5 O exemplo não se esgota na cuia. O pensamento que conquistou tal abstração se predispõe a evoluir, a se tornar ainda mais abstrato, e a relacionar outros objetos díspares, como a lança, com a cuia. Através da equivalência duas lanças passam a equivaler uma cuia, que por sua vez equivale a 3 flechas $(2 \mathrm{~L}=1 \mathrm{C}=3 \mathrm{~F})$. Ao se expressar proporções usamos o sinal de igualdade, o que faz com que $2 \mathrm{~L}=1 \mathrm{C}=3 \mathrm{~F}$. Os termos podem ser rearranjados, desde que não se altere as proporções, de forma que outra possibilidade de se expressar essa relação é $1 \mathrm{C}=2 \mathrm{~L}=3 \mathrm{~F}$. Decerto, tal equação é bastante rígida, e pode ser relativizada, se ao invés de números absolutos utilizássemos variáveis (ao invés do multiplicador 2, a variável "a"; e ao invés de 3 , "b"). Com isso teríamos $C=a L$, para nos atermos aos dois primeiros elementos. Tais elementos podem ser incrementados sem perder a proporcionalidade, de forma que $2 \mathrm{C}=2 \mathrm{aL}$, ou melhor, $\mathrm{C}_{2}=\mathrm{aL}_{2}$. Se $\mathrm{C}_{2}=\mathrm{aL}_{2}$ e $\mathrm{C}_{1}=\mathrm{aL}_{1}$, então $C_{2}-C_{1}=a L_{2}-a L_{1}$, ou $C_{2}-C_{1}=a\left(L_{2}-L_{1}\right)$, ou $C_{2}-$ $C=a\left(L_{2}-L\right)$. Agora, se seguirmos a orientaçã̃o 
de um homem que transcendia as ciências em seus estudos sobre o cálculo diferencial (MARX, 1983) e aplicássemos a tautologia em C, retirando a noção de proporção, teríamos $C_{2}=C$, que se resolve em $\mathrm{C}_{2}-\mathrm{C}=0$; o que tornaria a equação precedente $0=a\left(L_{2}-L\right)$. Por sua vez, e pelo mesmo princípio, $L_{2}=L$ se resolve em $L_{2}-L=0$, culminando na equação $0=$ a. 0 e ao número zero, vazio de conteúdo e por isso passível de ser preenchido de diversas formas.

${ }^{6}$ Sabe-se que 100 pedaços de chão do planalto paulista jamais serão 100 pedaços de chão amazônico, ainda que se altere a medida do pedaço (centímetros, metros, hectares, alqueires), por, de fato, existirem atributos espaciais, tema bastante íntimo dos geógrafos. 100 pedaços de chão do bairro de Pinheiros jamais serão 100 pedaços de chão do Jaguaré, pois a posição geográfica, para citar apenas um desses atributos, determina cada um desses fragmentos do território como único; por isso de se reportar a uma troca possível quando se sabe que ela é, materialmente, impossível. Daí da importância da mediação do pensamento abstrato para os objetos concretos: com ele o concreto se torna abstrato, e o abstrato, concreto; ou melhor ainda, o concreto se torna concreto-abstrato e o abstrato, abstrato-concreto, visto que ambos os termos se transformam após experimentarem o seu outro.

7 O novo termo $P$, sendo distinto da equação anterior, talvez merecesse uma revisão, e ser tratado por $\mathrm{P}^{\prime}$ ou $\mathrm{P}_{1}$, indicando haver um progresso. A fórmula seria, nesse caso, $P^{\prime}=\{p, o\}$. Existir um progresso, nesse caso, indica um reforço do termo. A nova Propriedade ( $\left.P^{\prime}\right)$ é mais potente que a primeira à medida que a permite se realizar de forma ainda mais abstrata, como será discutido nos próximos parágrafos, sem a presença do proprietário em período integral. Tal movimento é denominado de aprofundamento, em Lefebvre: "se o 'fim' de um progresso reencontra o seu começo, não temos aqui um círculo vicioso, mas uma superação real, na condição de que o progresso (..) seja efetivo e consista num aprofundamento do ponto de partida" Cf. LEFEBVRE, 1975, p. 233.
${ }^{8}$ A pergunta-chave de Lefebvre é: "como isso foi possível?". Tal pergunta se reitera no seu livro "Lógica Formal, Lógica Dialética" e embora não haja uma resposta única, ele sugere, em diversos momentos, pensar a divisão social do trabalho como um eixo potente para explicar a história da lógica, que é uma história social. Partindo dessa hipótese, ele expõe que existe, na história, um momento no qual "a vida social se diferencia e se aperfeiçoa; surge a divisão social do trabalho e, notadamente, a separação entre trabalho material e trabalho intelectual." (p. 54). Esse momento, potente, permitiu, na Grécia, o desenvolvimento do idealismo metafísico, calcado na "divisão das atividades humanas (divisão do trabalho, separação entre trabalho intelectual e trabalho material), com suas conseqüências: separação da teoria e da prática, da alma e do corpo, do pensamento e do objeto." (p. 77). "Essa separação entre o concreto e o abstrato, entre a contemplação e a ação, entre a teoria e a prática, (...) teve um fundamento social, a escravidão, pois todo trabalho prático e produtivo era abandonado aos escravos e o pensamento metafísico dos gregos foi uma ocupação aristocrática, um prazer luxuoso reservado aos homens livres" (p. 110). Alain Bihr, em texto-homenagem - como esse! - ao mestre, compartilha de suas idéias, acrescentando que é nesse momento histórico que se proliferam as trocas de mercadorias e de dinheiro, responsáveis pela dissolução do mundo mítico, também denominado erroneamente de primitivo (BIHR, 2001, p. 3).

9 A perspectiva de longa duração desse artigo não anula a especificidade que a propriedade tomou com o capitalismo, antes se compõe a ela. A citação de Seabra é um convite à visita do quarto capítulo de sua livre-docência: "A História mostra que o 'dono' e a propriedade puderam separarse porque foram estabelecidas, como prerrogativas do direito, por um processo convencionado em termos políticos, a estipulação do 'preço', como condição de mobilidade da propriedade. A Lei de Terras proibiu doação e estabeleceu a obrigatoriedade de compra e venda. Foi esse o fundamento pelo qual a propriedade, em princípio um direito, foi transformada numa variável econômica do capitalismo. As diferentes modalidades que essa 
forma econômica pôde assumir é, desde o século XIX, objeto de controvérsias, mas sob consenso de que a propriedade é um equivalente de riqueza, pois nada produz." (SEABRA, 2003, p. 340).

10 O progresso dos termos admite a superação parcial, provisória. Assim, a identidade traz, no seu subterrâneo, a tautologia. Não se vive uma nova abstração isoladamente (a identidade, apenas), mas todas as anteriores, sedimentadas (a tautologia e a identidade, juntas, somadas), em nova potência, revestidas por uma nova forma que Ihes emprega maior eficácia.

11 Para os povos bárbaros a Propriedade é, muitas vezes, aquilo que se veste, e é nesse sentido que se dão as relações sociais sob a ausência do contrato, e da forma mediadora do contrato, permissor da troca possível. O pertencimento a uma comunidade se rege com a presença do sangue dessa comunidade (ou se nasce, legitimamente, naquela comunidade, ou nunca se fará ser um membro dela); para um germano é filho todo aquele que "carrega" nas suas veias o seu sangue, sendo criado e cuidado como seu próprio devir.

12 Por sua vez, para o romano civilizado os estatutos são invertidos: a propriedade é pensada contratualmente, através da troca possível, valendo-se do princípio do domínio territorial, importando menos "vestí-la" e mais o exercício de sua defesa, pois enquanto essa puder ser feita, ao defensor pertencerá. Inverte-se também o pertencimento social, que se faz com a permanência do sujeito durante um ano e um dia na "cidade", e ainda a paternidade, realizada mediante o ato do pai em [a]colher o filho deixado pela parteira na sala, reconhecendo-o como coisa sua.

${ }^{13}$ Marx faz diversos apontamentos sobre a propriedade, e reconhece a importância da cisão entre posse e propriedade como um elemento precussor e alicerçante do capitalismo, nos Grundrisses (volume 2, principalmente) e no Capital. Ele indica que apesar de anterior, é no capitalismo que a condição de ser ou não proprietário se aprofunda e o embate se torna quotidiano, com a necessidade do capitalista em despojar dia após dia todos os entes da sociedade, inclusive seus concorrentes, proletarizando-os. Trata-se de um processo de expropriação necessário para a subsunção ao trabalho, visto que deve restar ao trabalhador apenas sua força de trabalho de forma que esse a coloque à venda, dia após dia, na hasta pública. Esse processo, cuja natureza é negativa, carrega, para o "jurista" Marx, um aspecto positivo, pois é mediante essa expropriação que se cria a possibilidade de se transformar o trabalhador em sujeito. Isso porque é necessária a condição de ser sujeito para que se possa dispor, livremente, de sua capacidade laboral aos interessados. É assim que surge o proletário, o trabalhador despossuído dos meios de produção mas dono de sua força de trabalho, sujeito potencial que é compelido, dia após dia, à sujeição ao trabalho, num processo no qual, contraditoriamente, quanto mais se embrenha mais se impossibilita a materialização da sua potencialidade (Cf. MARX, 2002). Embora esteja correto em todas essas acepções, Marx enfatiza por demais o caráter redefinidor do capitalismo e exaspera uma história muito curta, a desse sistema. Sua obra deixa, definitivamente, em aberto a questão da propriedade e o movimento da abstração. Uma falha que não invalida seu esforço teórico; outrossim suscita novos esforços e demonstra que ainda há muito a ser feito, sem dogmatismo. Não é com diletantismo que se faz menção a Lefebvre enquanto um continuador da obra de Marx. Seus estudos sobre a lógica apontam que uma história mais longa deve ser compreendida; o que se repete em Oswald e em Vaneigem, para os quais uma história de longa duração culmina no capitalismo, redefinidor de certas relações

${ }^{14}$ Os parênteses da equação precedente - $\mathrm{P}=$ $\{(\mathrm{p}+\mathrm{t}), \mathrm{o}\}$ - indicam que o tipo de solo (rural ou urbano) adentra à equação como uma qualidade da propriedade, não podendo, nesse momento, ser mobilizado. Difere, por sua vez, da posse (o), que pode ser posta à praça pública, a quem interessar, por se tratar de um elemento distinto no conjunto.

${ }^{15} \mathrm{~A}$ precisão dos instrumentos administrativos fez surgir, por exemplo, ruas em que um dos lados admite o comércio e o outro não. Se em exemplo passado a diferença entre o solo do Jaguaré e o de Pinheiros se dava principalmente pela localização (atributo imutável), com a implantação 
de um zoneamento, criou-se uma nova série de atributos, de ordem mutável, para a propriedade. Ainda que a distância espacial seja ínfima, de poucos metros, é bastante diferente, no mundo capitalista, um terreno com permissão de uso comercial daquele que pode ser, pela legislação urbana, empregado para residência apenas.

16 “A noção de solo criado desenvolveu-se inicialmente a partir da observação da possibilidade de criação artificial de área horizontal, mediante a sua construção sobre ou sob o solo natural. Compreendia-se assim o solo criado como o resultado da criação de áreas adicionais utilizáveis, não apoiadas diretamente sobre o solo natural. Não se confunde, no entanto, a noção - mesmo quando nestes termos entendida - com a de ocupação do espaço aéreo, visto que pode haver ocupação de espaço aéreo sem criação de solo; seria o caso de construção de uma torre de grande altura, sem pavimentos intermediários, ou de nave de uma catedral gótica também de grande altura, mas sem nenhum plano utilizado no intermediário. Por outro lado, pode haver criação de solo sem ocupação do espaço aéreo: seria o caso das construções no subsolo, que ocupam um espaço subterrâneo." (GRAU, 1983, p. 57).

${ }^{17}$ A crise não é externa, mas interna ao sistema. Num sistema crítico, como o capitalista, as contradições internas sugerem seu próprio limite e destino: a morte. O que não implica a noção de fatalidade (determinista). Sendo a natureza da crise endógena (como no caso de um conteúdo que cresçe mais que a forma, força- a a se romper, e com ela, a derramar a si próprio), a fatalidade se daria apenas sem intervenções exteriores (essa tendência ao encontro dos seus limites é considerada sem a intervenção de terceiros). O que sugere haver possibilidade de continuidade da vida desse organismo, ainda que de maneira crítica, com a adoção de intervenções exteriores (como aquelas que lhe mudem a forma, ampliando-a e fazendo com que o conteúdo sobreviva ao invés de se esgotar por suas próprias contradições).

${ }^{18} \mathrm{O}$ direito positivo reconhece um passado onde imperou toda ordem de constrangimentos e coações pessoais, ao qual se opõe. Ele é fruto de um idealismo que pensa poder eliminar, num só golpe, todo esse passado, inaugurando uma nova sociedade, livre dessas violências. Essa nova sociedade seria instituída pela lei, expressão da razão, da transparência, da pureza... De forma que, no lugar dos mandos pessoais, haveria a vontade da lei, a vontade da razão, cumprida com orgulho pelos cidadãos cientes de que ao fazê-lo obedeceriam não aos reis ou governantes, mas à própria sociedade. Esse reino da razão foi muitas vezes acusado de fazer tábula rasa do passado - especialmente em nosso país - ao desconsiderar a história e almejar reinaugurá-la à força; contudo essa razia é expressão nítida de um profundo conhecimento do passado e de uma vontade imensa em tomar as rédeas do futuro para que nele tais violências não mais aconteçam. É a possibilidade de se criar, efetivamente, um novo mundo, mais belo, para todos. Fazendo um salto, quase mortal, pode-se, com efeito, dizer que esse é o sentido do zoneamento urbano: propiciar uma cidade mais bela, com um horizonte harmonioso, sem grandes rupturas, com ruas e calçadas largas, responsáveis por uma boa ventilação, às custas de um cerceamento do direito de propriedade naquilo que tange à altura edificável dos imóveis e de seu uso. Uma cidade bonita, gostosa de morar, expressão da espécie humana, dizem os idealistas, compeliria todos a exercerem seus direitos com certos limites, com razoabilidade, para não invadirem o direito dos demais. Os motivos dessa cidade não se concretizar são inerentes a esse pensamento [idealista], que desconhecendo a materialidade da sociedade, sonha em concretizar, pela força de idéias, um mundo utópico abstrato.

19 Direito Real ou Direito de Rei. Embora haja toda uma classificação moderna dada pela ciência jurídica, parece certo que o adjetivo advém da condição ímpar de se poder dispor livremente, como um rei, do objeto de direito. Não por menos esta é a definição mais corrente de propriedade territorial (no inglês o é termo Real Estate, sendo Real, nesse caso, uma derivação de Royal, coisa de rei). O processo de abstração da propriedade admite, também, um movimento que vai da condição de coisa à situação de sujeito. Um certo individualismo prometeu a todos homens a possibilidade de serem reis na terra, de se tornarem indivíduos; enfim, do homem comum 
ser alguém. Promessa que não se efetivou em sua plenitude, mas que permanece até hoje latente, representando um certo progresso. Esse tema, numa primeira variação, incompleta, está presente no meu "Anotações sobre a história do Público: Contribuição para a análise geográfica do social moderno a partir do bairro de Pinheiros, São Paulo", cuja leitura se faz sugerida.

20 Nos documentos da Municipalidade, a definição de Operação Urbana consta como: “Uma Operação Urbana é a execução de um plano de renovação, promovido em porções do território municipal, cuja potencialidade de desenvolvimento apresenta-se ampliada em razão de investimentos públicos, realizados ou propostos, e onde existe interesse da Municipalidade e de agentes privados na sua promoção. A oportunidade da ação está, em geral, relacionada à possibilidade do investimento público em capacitar uma área envoltória para a intensificação de sua utilização, seja pela oferta de infra-estrutura suplementar, seja pela neutralização ou supressão de fatores de desqualificação ambiental. A viabilidade econômica da intervenção depende do interesse dos investidores privados em adquirir, da Prefeitura, direitos adicionais aos da legislação regular de zoneamento." (SÃO PAULO (Cidade), 2000 , p. 6). Em resumo forçado, a modalidade Operação Urbana é caracterizada por um perímetro previsto em lei (o que evita ações jurídicas de inconstitucionalidade, como no caso das Operações Interligadas), uma quantidade igualmente limitada de metros quadrados virtuais (metros edificáveis além do zoneamento, solo criado) a serem vendidos para empreendimentos interessados em edificar além do permitido pelo zoneamento original do local, um conjunto de ações (ou investimentos em aparelhos urbanos) que tornam a área interessante para novos empreendimentos, e uma conta própria para gerir os valores recebidos pela venda dos metros quadrados (virtuais) edificáveis que ultrapassarem o zoneamento original da área.

21 A extrapolação do zoneamento deve ser compreendida para além de seu aspecto negativo. Ao criar um limite, ainda que fictício, para as construções, a lei de zoneamento criou, para a cidade, um limite de reprodução do capital. Essa barreira é superada por títulos que se compõe à lei do zoneamento para incrementar seus limites, decretando que a cidade adentrou a um novo tipo de direito, o qual pode ser rascunhado sob a noção de "direito permissivo oneroso". Esse tema será desenvolvido em outro artigo por ocasião do conceito de Estado Interventório de Urgência.

22 A crise se evidencia pela necessidade de criação de complexos instrumentos jurídicos (como o das Operações Uibanas) para quecontinuem a ser lucrativos os negócios envolvendo as construções na cidade, pois de outro modo a necessária destruição de valor (compreendidos como a compra de sobrados ou pequenos prédios para demolição, que dada sua localização - um atributo espacial - apresentam grande custo) para edificação em maior escala (torres de escritórios ou apartamentos) tornaria os lucros demasiados pequenos - ou nulos -, visto que essa construção seja limitada em número de andares pelas regras do zoneamento urbano. A introdução desses instrumentos renova a possibilidade desses negócios, na medida em que se pode extrapolar o gabarito urbano com a aquisição de títulos públicos, que normalmente são negociados com certo "desconto" (em comparação ao custo do $\mathrm{m}^{2}$ na região, caso existisse algum terreno disponível).

23 "O direito de superfície é o direito real de construir ou plantar em solo alheio. / Trata-se de direito real sobre coisa alheia, já que não afeta o domínio do proprietário do solo. Um aspecto que os autores salientam com relação ao direito de superfície é o fato de que ele afasta a acessão, ou seja, a regra segundo a qual todas as coisas que se acrescentam ao solo, sejam plantações ou construções, pertencem ao dono do solo (superfícies solo cedit). Tal regra, no Direito Brasileiro, consta do art. 545 do Código Civil Brasileiro, segundo a qual 'toda construção, ou plantação, existente em um terreno, se presume feita pelo proprietário e à sua custa, até que o contrário se prove'. / No caso do direito de superfície, enquanto o mesmo perdura, a propriedade do dono do solo coexiste com a propriedade do dono das plantações ou construções que se acrescentam ao solo. Tratase de exceção ao princípio de que o acessório segue o principal". (PIETRO, 2002, p. 172).

24 A gleba da Telefônica pertencia originalmente ao poder público, mais precisamente à Estatal TELESP (Telefonia de São Paulo). Com a privatização, todo seu patrimônio foi incorporado ao da Telefônica, e assim essa grande gleba 
adentrou ao patrimônio da empresa espanhola, embora esse não fosse seu interesse direto. O que não significa que haja um desinteresse por parte da Telefônica quanto a essa gleba, pois a história brasileira é rica em exemplos de negócios modernos que se combinam a outros mais antigos, especialmente os vinculados à propriedade da terra (vide, por exemplo, os negócios da Light com a retificação dos rios Pinheiros e Tietê, cf. SEABRA, 1986).

${ }^{25}$ As glebas da CPTM e da Municipalidade, por serem terras do poder público, apresentam dificuldades formais para adentrarem no mundo dos negócios. Por ocasião do princípio da indisponibilidade, o poder público não pode, como um particular, dispor de seu patrimônio, senão por ritos muitos complicados, o que torna sua compra e venda quase impossível de se operar. A viabilidade dos negócios, nesse caso, se dará sem a compra e venda de propriedades, mas com uma Parceria Público-Privada envolvendo, outrossim, a exploração dessa superfície, contornando os impedimentos mais usuais do direito Administrativo e da legislação pública.

${ }^{26}$ No exemplo sugerido não existirá venda e compra de imóvel. O que estará em negociação será o direito, outrossim, de morar. Por isso mesmo não serão garantidos os direitos de quem compra um imóvel, vez que não se estará negociando a propriedade, mas coisa diversa, como num leasing, que é um aluguel com opção de compra.

27 O usucapião pressupõe um certo abandono ou desprezo por parte do proprietário, que desinteressado pela sua propriedade, deixa de exercer seu domínio por longo período de tempo. Ele não é possível em terrenos públicos (pelo princípio da indisponibilidade, dentre outros) e tampouco é admitido em casos onde há contratos, que pressupõe a presença do domínio. Assim, uma locação de 20 anos consecutivos não gera direito de usucapião, por ser uma negociação entre as partes; entretanto, uma ocupação por tal período, sem manifestação do proprietário, permite ao posseiro usucapir o terreno alheio, por posse mansa.

${ }^{28}$ A proposta desse quadro é apresentar a propriedade enquanto um movimento de abstração, de forma que ele não se pretende exaustivo. Contudo, qualquer contribuição que o torne mais completo será bem-vinda.

${ }^{29}$ Sobre a propriedade do dinheiro, Harvey menciona que: "O dinheiro existe como uma forma de propriedade capitalista que se encontra fora de qualquer processo de produção real, e é independente a ele. Aqui surge uma distinção entre os capitalistas como donos do dinheiro e como empregadores do capital, que usam esse dinheiro para estabelecer o necessário para a produção de mais-valia. A atividade de emprestar e de pedir emprestado estabelece uma relação entre esses dois tipos diferentes de capitalistas. Marx expõe essa relação da seguinte forma. Os proprietários do dinheiro tratam de aumentar seu capital emprestando a juros, o que implica uma forma de circulação da ordem $D-(D+j)$. Suponha que se empreste dinheiro a um capitalista que se dedica à produção, e que não tem recursos monetários próprios.". Ao final do processo, parte da mais-valia conseguida com a produção desse capitalista iria para o pagamento dos juros do dinheiro emprestado pelo outro capitalista, "e assim, argumenta Marx, a maisvalia se divide entre os possuidores do capital a juros e os empregadores do capital que recebem os lucros da empresa". A propriedade do dinheiro não criou, por ela mesma, valor, mas capturou valores da produção uma vez que foi operada a juros. (HARVEY, 1990, p. 260-261).

30 Nesse ponto é importante ressaltar que as empresas em si não "criam" softwares ou músicas; outrossim elas compram de quem os produz, através do pagamento de salários a programadores ou de direitos autorais a quem canta ou compõe. O programador de computadores, o cantor, ou o escritor - o que faz esse artigo, por exemplo! - possui, como sua, a força de trabalho. Ele a coloca à venda, como proprietário, na feira pública. Por sua vez, o capitalista a compra, faturada em até 35 dias (paga-se no 5ㅇ dia subsequente ao mês trabalhado), dando em troca sua propriedade, o dinheiro.

${ }^{31}$ O software adentra o circuito da mercadoria na medida em que é empregado na produção e na distribuição. Em termos simples, a tecnologia adentra as linhas de montagens para gerar maior produtividade e competitividade às empresas 
através de técnicas mais modernas de comunicação e controle da produção. O empreendimento comercial ou industrial pode desenvolver seus programas de controle (mantendo uma equipe de analistas e programadores) ou adquirir licenças de quem realiza esse tipo de $P \& D$ na praça pública, o que é mais comum, por envolver gastos menores. Por sua vez, nesse segundo caso, a empresa de programas de computadores ao vender licenças de seus produtos, adentra à produção analogamente ao possuidor de capital a juros. Ela, com seus softwares de controle, viabiliza a produção dentro das médias sociais e, dessa produção, retira uma parte da mais-valia do processo, que se funda sempre na produção.

${ }^{32}$ Maiores detalhes dessa história podem ser obtidos nos livros indicados na bibliografia e no último capítulo das dissertação de mestrado "O metrô chega ao centro da Periferia".

${ }^{3}$ A GPL, ou General Public Licence (Licença Pública Geral), é o termo que rege esse tipo de propriedade. É um tipo especial de licença (ou decalque da propriedade) que, como outras licenças, não vende a propriedade, mas permite seu uso quase irrestrito por outras pessoas, desde que seus termos sejam respeitados. Dentre eles há uma cláusula de preço, por assim dizer, que curiosamente não taxa as pessoas a pagarem dinheiro algum, mas a tornar igualmente GPL qualquer modificação, perpetuando o ciclo.

34“Esta sociedade não obedece a uma lógica, repitamos-lo uma vez mais: tende para ela. Esta sociedade não representa um sistema; se esforça em sê-lo, reunindo o constrangimento e a utilização das representações." (LEFEBVRE, 1976, p. 42). Ainda sobre a lógica, Damiani esclarece que "No nível do real e no nível da representação, nossa época, aquela da reprodução das estruturas da sociedade moderna, faz a lógica se tornar real, não só pensamento*. Somente considerando a interferência da lógica na realidade concreta, como estratégia, como sóciológica é possível compreender essa outra dialética e estabelecer a passagem das contradições no espaço para aquelas do espaço." (DAMIANI, 2004, p. 85). E, em nota, Damiani complementa: * "Trata-se de uma das contribuições mais significativas da obra de Henri Lefebvre. Em escritos do autor, datados de 1983-84, ele, ainda, assinala que, mesmo em termos metodológicos, é possível examinar de perto e desenvolver o pensamento de Marx, completando-o. É preciso sublinhar que a lógica fez grandes progressos; 'que se tornou operatória, isto é, que ela entra na prática social; e isto cada vez mais com suas aplicações que vão da organização do trabalho produtivo ao emprego militar e político dos computadores. Como não reconsiderar as relações da lógica e da dialética? Mesmo se permanecermos ligados a esta última, mesmo se continuarmos a compreender, no sentido de Hegel e Marx, o 'trabalho do negativo' (e isto no curso do que se chama a 'crise'), uma problemática nova surge das relações entre a lógica e a dialética'. (Revue La Somme et le Reste - Études Lefebvriennes, 2002)."

35 Compeende-se nessa telescopagem uma complexidade que extrapola a resolução da condição público-privado da propriedade, e abarca o formato da Produção na discussão, a qual passa a ser autogestionada, mediante um constante processo de pedagogia dos atores envolvidos. Esse é o maior ensinamento que Eric Raymond extraiu do seu trabalho de campo "implicado", que consistiu na manutenção de um sistema regido pela GPL. Parte dessa experiência está reportada no texto-manifesto "A Catedral e - Bazar". A leitura desse texto revela, induvidavelmente, uma profunda mudança nas relações sociais sob a GPL, sendo Raymond, naquele momento, sua expressão.

36 A concessão de uso especial para moradia (MP 2.220/2001), medida através da qual o poder público cederia áreas públicas para particulares que as tivessem ocupado por mais de 5 anos, carrega consigo uma série de avanços e também imperfeições. Dentre os avanços havia, nos artigos vetados do Estatuto da Cidade, a possibilidade de concessão coletiva, o que a aproximaria da propriedade comunal. Quanto aos aspectos negativos, basta lembrar que esse instrumento não elimina a titularidade da terra, de modo que o poder Público pode intervir em sua concessão direcionando a população para outra área, nas várias hipóteses elencadas no artigo 5으, realizando uma economia política do espaço. Esse é o seu lado mais visível. Existem outros, escondidos nos porões do Direito, como 
demonstram os juristas em seus estudos (DALLARI e FERRAZ, 2002, p. 166)

37 A Propriedade territorial, se pensada enquanto mercadoria, possui, dentre outros limites, o da reprodução. A porção de terra emersa não é reproduzível como os demais bens (carros, eletrodomésticos, etc), na medida em que é finita.

${ }^{38}$ A negação direta da propriedade, altamente radical, não se compõe à lógica interna do processo. Não é procedimental, e não está inserida numa luta quotidiana. O que não significa que deva ser abandonada. Ao contrário, deve-se tê-la presente, como norteadora das ações procedimentais, capazes de minar paulatinamente o sistema em seu interior, corroborando assim para sua dissolução. Ela também deve, a seu tempo, se efetivar.
39 O Direito moderno possui uma história, a da tutela dos direitos individuais. Assim, a noção moderna de Estado de Direito, de Estado submerso às leis, coage todo aparato estatista a reconhecer e respeitar os direitos individuais, que incluem o da propriedade. Embora um cientista do Direito possa escrever inúmeras laudas sobre a primazia dos direitos sociais face aos individuais, o bom operador do Direito sabe que sua demanda dificilmente deixará de ser apreciada se envolver um direito individual, enquanto que, se pleitear um direito social, estará sujeito ao [des]preparo do julgador para essa espécie de litígio, lançandose numa zona cinzenta, com possibilidades remotas de vitória. Um trabalho esclarecedor a respeito desse tema é o de LOPES, 1994.

\section{Bilbiografia}

ANDRADE, Oswald. A utopia antropofágica (coletânea). São Paulo: Globo, 1995

ARANTES, OTILIA et alli. A cidade do pensamento único: desmanchando consensos. Rio de Janeiro: Petrópolis, 2002

BAITZ, Ricardo. Anotações sobre a história do público: contribuição para a análise geográfica do social moderno a partir do bairro de Pinheiros, São Paulo. In: CD-Rom IX Simpurb (Simpósio Nacional de Geografia Urbana), Manaus: UFAM, 2005.

BAITZ, Ricardo. O metrô chega ao centro da periferia: estudo do concurso público nacional de reconversão urbana do Largo da Batata e da operação urbana Faria Lima em sua nova fase (dissertação de mestrado). São Paulo: Departamento de Geografia da Faculdade de Filosofia, Letras e Ciências Humanas da Universidade de São Paulo (DG-FFLCH/USP), 2004

BAITZ, Ricardo. Para uma Egogeografia Pinheiros: aspectos de um bairro metropolitano vol. 2 (dissertação de mestrado). São Paulo. Faculdade de Filosofia, Letras e Ciências Humanas, Departamento de Geografia, 2004
BAUDRILLARD, J ean. O sistema dos objetos. São Paulo: Perspectiva, 1993.

DALLARI, Adilson Abreu e FERRAZ, Sérgio (coordenadores). Estatuto da Cidade: comentários à Lei Federal 10.257/2001. São Paulo: Malheiros, 2002

DAMIANI, Amélia Luisa. A propósito do espaço urbano: algumas hipóteses. In: CIDADES: Revista científica. Vol 1, no 1. Presidente Prudente: Grupo de Estudos Urbanos, 2004-

DAMIANI, Amélia Luisa; CARLOS, Ana Fani Alessandri, SEABRA, Odette Carvalho de Lima (organizadoras). O espaço no fim de século: a nova raridade. São Paulo: Contexto, 1999

GRAU, Eros Roberto. Direito Urbano: Regiões metropolitanas, Solo criado, Zoneamento e Controle Ambiental, Projeto de Lei de Desenvolvimento Urbano. São Paulo: Editora Revista dos Tribunais, 1983

HAARMANN, Petra. Copyright und Copyleft: Vermittlung im Falschen oder falschen Unmittelbarkeit. (texto disponível no sítio da revista Exit!, em www.exit-online.org/pdf/ Exit0108PHCopyleft.pdf). Alemanha, 2004 
HARVEY, David. Los límites del capitalismo y la teoría marxista. México: Fondo de Cultura Economica, 1990

HARVEY, David. Spaces of Capital: towards a Critical Geography. New York: Routledge, 2001

HUEBNER, Rudolf. A history of germanic private law. New York: Augustus M. Kelley Publishers, 1968

HUIZINGA, Johan. Homo Ludens: o jogo como elemento da cultura. São Paulo: Perspectiva, 2004

KURZ, Robert. Novas relações sociais não podem ser criadas por novas tecnologias. Entrevista disponível na internet em www.unisinos.br/ihu/ boletim/edicoes/boletim00161.doc. São Leopoldo, 2005

LEFEBVRE, Henri. Espacio y Política: El derecho a la ciudad II. Barcelona: ed. Península, 1976

LEFEBVRE, Henri. La production de l'espace. Paris: Anthropos, 2000

LEFEBVRE, Henri. Lógica formal / lógica dialética. Rio de Janeiro: ed. Civilização Brasileira, 1975

LOPES, José Reinaldo de Lima. O direito subjetivo e direitos sociais: o dilema do judiciário no Estado Social de Direito. In: FARIA, J ose Eduardo (org). Direitos Humanos, Direitos Sociais e Justiça. São Paulo: Malheiros, 1994

MARX, Karl. Elementos fundamentales para la crítica de la economía política (Grundrisse). México: Siglo Veintiuno, 1988

MARX, Karl. Manuscritos Econômico-Filosóficos. São Paulo: Martin Claret, 2002

MARX, Karl. Mathematical Manuscripts. New York: New Park Publications, 1983

PIETRO, Maria Sylvia Zanella Di. Direito de Superfície in DALLARI, Adilson Abreu e FERRAZ, Sérgio (coordenadores). Estatuto da Cidade: comentários à Lei Federal 10.257/2001. São Paulo: Malheiros, 2002
RAYMOND, Eric S. A Catedral e o Bazar (texto disponível na Internet em http://unix.pro.br/ Artigos/Artigos/A_Catedral_e_o_Bazar/30/)

SÃO PAULO (Câmara da Cidade). Relatório Final (texto sem revisão) da Comissão Parlamentar de Inquérito para apurar irregularidades acerca da Operação Urbana Faria Lima, recentemente regulamentada através do decreto $\mathrm{n}$ - 41.257/ 01 (RDP 0084/2002). São Paulo, 2002

SÃO PAULO (Câmara da Cidade). Relatório Final da Comissão Parlamentar de Inquérito para apurar as Operações Interligadas (Leis no. $10.209 / 86$ e no. $11426 / 93$ ) realizadas no Município de São Paulo desde a promulgação da lei no. 10.209/86. São Paulo, 2001

SÃO PAULO (Cidade) Secretaria Municipal do Planejamento. Operação Urbana Faria Lima. São Paulo, 2000

SEABRA, Odette Carvalho de Lima. A insurreição do uso. In: MARTINS, José de Souza (org). Henri Lefebvre e o retorno à dialética. São Paulo: Hucitec, 1996.

SEABRA, Odette Carvalho de Lima. Urbanização e Fragmentação: Cotidiano e vida de bairro na metamorfose da cidade em metrópole, a partir das transformações do Bairro do Limão (tese de livre docência). São Paulo: Departamento de Geografia da Faculdade de Filosofia, Letras e Ciências Humanas da Univerdade de São Paulo, 2003.

VEYNER, P. História da Vida Privada, vol. I Do Império Romano ao ano Mil. SP, Cia das Letras, 1989

WILLIAMS, Sam. Free as in Freedom: Richard Stallman's crusade for free software. EUA: CA, 2002. Texto disponível na internet, em http:// www. faifzilla.org

WOLFF, Robert Paul, MOORE Jr, Barrington et MARCUSE, Herbert. Crítica da Tolerância Pura. Rio de Janeiro: Zahar editores, 1970

Trabalho enviado em julho de 2007 e aceito em agosto de 2007 